\title{
A Randomized Trial of Endovascular Embolization Treatment in Pelvic Congestion Syndrome: Fibered Platinum Coils versus Vascular Plugs with 1-Year Clinical Outcomes
}

\author{
Jose A. Guirola, MD, Maria Sánchez-Ballestin, MD, \\ Sergio Sierre, MD, Celia Lahuerta, MSc, \\ Victoria Mayoral, MD, PhD, and Miguel A. De Gregorio, MD, PhD
}

\section{ABSTRACT}

Purpose: To compare safety and efficacy of vascular plugs (VPs) and fibered platinum coils (FPCs) for embolization in pelvic congestion syndrome (PCS).

Materials and Methods: A randomized, prospective, single-center study enrolled 100 women with PCS from January 2014 to January 2015. Patients were randomly assigned to 2 groups, and embolization was performed with FPCs (n = 50) or VPs $(\mathrm{n}=50)$. Mean age of patients was 42.7 years \pm 7.60 , and mean visual analog scale (VAS) score for pelvic pain before treatment was $7.4 \pm 7.60$. Primary outcome (clinical success at 1 y using a VAS), number of devices, procedure and fluoroscopy times, radiation doses, costs, and complications were compared, and participants were followed at 1, 3, 6, and 12 months.

Results: Clinical success and subjective improvement were not significantly different at 1-year follow-up (89.7\% for FPCs vs $90.6 \%$ for VPs; $P=.760)$. Mean number of devices per case was $18.2 \pm 1.33$ for FPCs and $4.1 \pm 0.31$ for VPs $(P<.001)$. Three FPCs and 1 VP migrated to pulmonary vasculature approximately 3-6 months after the embolization procedure; all were retrieved without complications. The FPC group had a significantly longer fluoroscopy time (33.4 min \pm 4.68 vs $19.5 \mathrm{~min} \pm 6.14)$ and larger radiation dose (air kerma $948.0 \mathrm{mGy} \pm 248.45$ vs $320.7 \mathrm{mGy} \pm 134.33$ ) (all $P<.001$ ).

Conclusions: Embolization for PCS resulted in pain relief in 90\% of patients; clinical success was not affected by embolic device. VPs were associated with decreased fluoroscopy time and radiation dose.

\section{ABBREVIATIONS}

FPC $=$ fibered platinum coil, $\mathrm{PCS}=$ pelvic congestion syndrome, VAS $=$ visual analog scale, $\mathrm{VP}=$ vascular plug

From the Minimally Invasive Techniques Research Group (GITMI) (J.A.G., M.S.-B., S.S., C.L., V.M., M.A.D.G.), University of Zaragoza, Domingo Miral $\mathrm{s} / \mathrm{n}$, Zaragoza 50009, Spain; Centro de Investigación Biomédica en Red Bioengineering, Biomaterials and Nanomedicine (CIBER-BBN) (M.A.D.G.), Madrid, Spain; and Interventional Radiology (S.S.), Pediatric Hospital J.P. Garrahan, National University of Córdoba, Córdoba, Argentina. Received May 3, 2017; final revision received September 12, 2017; accepted September 14, 2017. Address correspondence to M.A.D.G.; E-mail: mgregori@unizar.es

None of the authors have identified a conflict of interest.

() SIR, 2017

J Vasc Interv Radiol 2017; -1:1-9

https://doi.org/10.1016/j.jvir.2017.09.011
Pelvic congestion syndrome (PCS) usually manifests as a dull chronic pain in the lower abdomen that can be intensified by the Valsalva maneuver or standing in the upright position owing to pelvic venous incompetence. The pathology is poorly understood and may result from pelvic valvular insufficiency and altered vein walls secondary to multiple pregnancies or high estrogen levels, leading to incompetent veins, blood stasis, and retrograde blood flow in the pelvic vasculature $(1,2)$. At the present time, the treatment of choice for pelvic varicose veins is sclerotherapy followed by embolization with coils, or just coil embolization (3-8). The embolization procedure is a simple technique with a success rate of $98 \%-100 \%$ in all cases 


\section{EDITOR'S RESEARCH HIGHLIGHTS}

- Embolization for treatment of pelvic congestion syndrome is effective, resulting in pain relief in $90 \%$ of patients, with durable symptom relief at 1 year.

- Should patient symptoms persist for 30 days after initial embolization, consider repeat imaging to evaluate for persistent or recurrent varices that may require additional embolization.

- Embolization device, either plugs or coils, did not impact clinical outcomes after embolization for PCS.

(3-7). Symptoms improve in $>66 \%$ of all patients (8), with improvement achieved in $80 \%-93 \%$ at $1-5$ years of follow-up (5-7). Recurrence is rare, but some authors have reported recurrence rates of $5 \%-42 \%$ in patients treated with embolization $(3-7,9,10)$. Despite the excellent published results, the most important disadvantages of this treatment are the possibility of coil migration and the extensive procedure time and irradiation dose received in the pelvic area $(7,11)$.

Vascular plugs (VPs) are well-established embolic devices that can be an excellent alternative to coils for embolization of medium-sized to large-sized arterial or venous vessels (12). Multiple clinical applications have been described since the introduction of VPs in 2004, but randomized studies have been performed only to compare arterial embolization or variceal embolization after transjugular intrahepatic portosystemic shunt procedures (13-15). There are fewer publications related to the use of VPs in peripheral venous embolization. Among recent studies, only 2 have used VPs to treat PCS $(16,17)$, but no randomized studies exist. Lopez (18) suggested embolization of pelvic venous plexus to treat the entire vessel, including the larger truncal draining tributaries to prevent new collateralization, which would increase the number of devices used. This prospective randomized study compared the safety and efficacy of 2 embolic agents for treating PCS: fibered platinum coils (FPCs) and VPs. This randomized controlled trial was performed to test the hypothesis that venous embolization for PCS with VPs could reduce the number of embolic devices and procedure time without significant differences in the clinical success or complication rate compared with embolization performed with FPCs.

\section{MATERIALS AND METHODS}

\section{Study Design}

This randomized controlled parallel trial was approved by the regional and institutional review board (reference number PI14/000164), registered at ClinicalTrials.gov (NCT02796092), and conducted in accordance with the principles of the Declaration of Helsinki. Written informed consent was obtained from all participants for both the procedure and the study. Eligible patients were randomly assigned to 2 groups following block randomization
(4 patients in each block) for treatment with either FPCs or VPs at a 1:1 ratio (Figs 1, 2). All patients were recruited from January 2014 to January 2015. The primary outcome was clinical success as subjectively assessed by the patients. Secondary outcomes were complications, need for re-embolization secondary to lack of improvement, recurrence of initial symptoms or transvaginal Doppler ultrasound revealing venous reflux or venous diameter $>6 \mathrm{~mm}$, procedure time, fluoroscopy time, radiation dose, and cost.

\section{Study Population and Eligibility}

The study was carried out in a single center. All patients were referred from a vascular surgeon, underwent transvaginal Doppler ultrasound to diagnose PCS and pelvic varices, and met the eligibility criteria (Table 1). Diagnosis of PCS involved a combination of symptoms and ultrasound findings (Fig 2). Baseline patient data are presented in Table 2.

\section{Randomization and Blinding}

Patients were enrolled in the study by a vascular surgeon who referred the patients to the interventional vascular unit. The team epidemiologist generated a random allocation sequence using Research Randomizer Version 4.0 (19), and the research nurse assigned eligible patients to the FPC or VP group. All patients were blinded to the device used. The performing radiologists were not blinded, but the interventional radiologists performing the clinical follow-up were blinded to group allocation.

\section{Sample Size}

Assuming that both methods were equally effective based on the experience of the research group and the literature (13), the primary outcome (ie, clinical success) was not used to calculate the sample size. Instead, sample size was determined by computer software $\left(\mathrm{G}^{*}\right.$ Power 3.1 ; Universität Kiel, Kiel, Germany) using retrospective data from patients seen in 2013 (7), comparing the mean total procedure time for both methods (41.2 $\mathrm{min} \pm 4.66$ vs $35.0 \mathrm{~min} \pm 4.43$ ). To detect the above-mentioned differences with an $\alpha$ error of .05 and $80 \%$ power using a 2 -sided test, 10 patients in each group was considered enough. As the annual volume of referral of patients with PCS to the interventional vascular unit was higher, it was decided to include 50 patients in each group.

\section{Baseline Data}

Mean patient age was 42.7 years \pm 7.60 (range, 29-60 y). Patients had a mean of 1.85 children \pm 0.88 and reported an initial mean visual analog scale (VAS) score of $7.4 \pm 1.34$. The patients receiving VPs were older $(44.3 \mathrm{y} \pm 8.45$ vs $41.0 \mathrm{y} \pm 6.26 ; P=.004$ ) and had worse pain (VAS median score 7.00 vs. $8.00 ; P=.004)$. No other baseline factors were significantly different between the 2 groups (Table 2 ). 


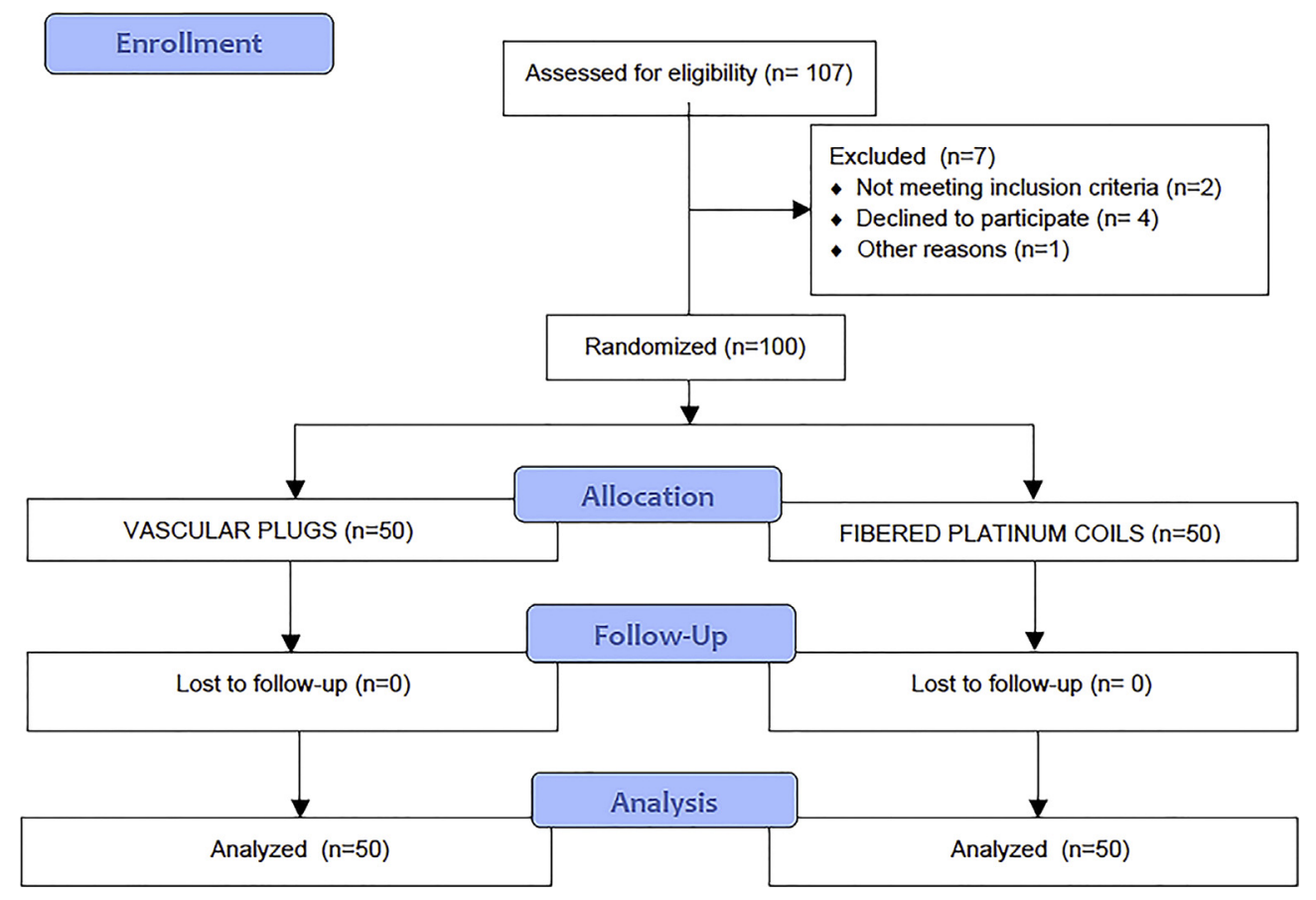

Figure 1. Consolidated Standards of Reporting Trials flow diagram.

\section{Technique}

The same team (interventional radiologist [M.A.D.G.] and assistant nurse, both with $>30$ years of experience in the field) performed all embolization procedures. The same angiography catheterization laboratory with an Allura Xper Philips FD20 (Philips Medical Systems Nederland BV, Best, Netherlands) was used. All procedures were carried out with a low fluoroscopy pulse rate (15 pulses/s, $10-\mathrm{ms}$ pulse) with a $0.9-\mathrm{mm}$ copper and $1-\mathrm{mm}$ aluminum filters. A $48-\mathrm{cm}$ field of view, which presented a total radiation dose of 24 $\mu \mathrm{Gy} / \mathrm{min}$ in a methacrylate phantom of $20 \mathrm{~cm} ; 3$ frames/s was chosen for pelvic or abdominal digital subtraction angiography studies. The preferred vascular access was the right internal jugular vein or the left if it was not accessible ( $\mathrm{n}=3$ patients). A $10-\mathrm{cm}, 6-\mathrm{F}$ introducer sheath (Radifocus; Terumo Europe, Leuven, Belgium) was used for the FPC procedures, and a 90-cm, 7-F introducer sheath (Flexor Raabe Guiding Sheath; Cook Medical, Bjaeverskov, Denmark) was used for the VP procedures. A C2, MPA, or SIM2 catheters (Impress Peripheral Angiographic Catheters; Merit Medical, South Jordan Utah) over a hydrophilic guide wire was used to target the ovarian and internal iliac veins. Embolization was started in the right ovarian vein, followed by the left ovarian vein, and finishing with the internal iliac veins (right and left). Embolization of all venous plexuses was performed at the lower aspect of the veins where all collateral veins converge to avoid occlusion of the deep pelvic plexus. In the FPC group, several 0.035 -inch Nester coils (Cook Medical) of different sizes $(8-20 \mathrm{~mm}$ in diameter, 7 or $14 \mathrm{~cm}$ in length) were used until complete occlusion of the 4 targeted veins was achieved. The unit price was $162.0 €$. In the VP group, an 8- to 22-mm Amplatzer
Vascular Plug II (St. Jude Medical, St Paul, Minnesota) was used, with a unit price of $880.0 €$. All the devices were oversized depending on the targeted vessel and the experience of the interventional radiologist (7); it was oversized approximately $1-2 \mathrm{~mm}$ in all targeted vein axes, corresponding to an oversize of $20 \%-35 \%$ in ovarian veins and $15 \%-20 \%$ in internal iliac veins. Occlusion was confirmed venography performed after embolization. During the intervention, the following data were collected by the data manager (V.M.) in an SPSS database (IBM SPSS Version 21.0; IBM Corp, Armonk, New York): number of devices deployed, occluded venous axis (left ovarian, right ovarian, left internal iliac, or right internal iliac), intervention time, fluoroscopy time, radiation dose (dose-area product [DAP] and air kerma), and any complication during the intervention. All patients were discharged 4 hours after the embolization procedure. No intravascular sclerotherapy or opioids for postoperative analgesia were administered.

\section{Outcomes}

Clinical success was defined as the relief of symptoms occurring before the procedure, including dyspareunia, dysmenorrhea, and urinary urgency (assessed by direct questioning before the procedure and at 1, 3,6, and 12 months) and subjective pain assessed by a VAS scored from 0 (no pain) to 10 (worst pain possible). Two categories were created: relief of symptoms (VAS score decrease $\geq 4$ points) and no improvement or worsening (new symptoms, increase or no change in VAS score, or improvement of VAS score $<3$ points) (7). Secondary endpoints were technical success (feasibility of embolization of the 4 targeted veins), number of devices used, total procedure time from venous puncture to venous 
Patients in follow up or treatment for lower limb varices (perfomed by angiologist \& vascular surgeon) Screening questionnaire for PCS

\begin{tabular}{|c|}
\hline Screening questionnaire for PCS \\
\hline Abdominal or chronic pelvic pain for more than 6 months? \\
Increased dysmenorrhea? \\
Dyspareunia? \\
Low back pain? \\
Visible varices in vulvar area and/or the groin? \\
\hline
\end{tabular}

If 3 or more answers positive

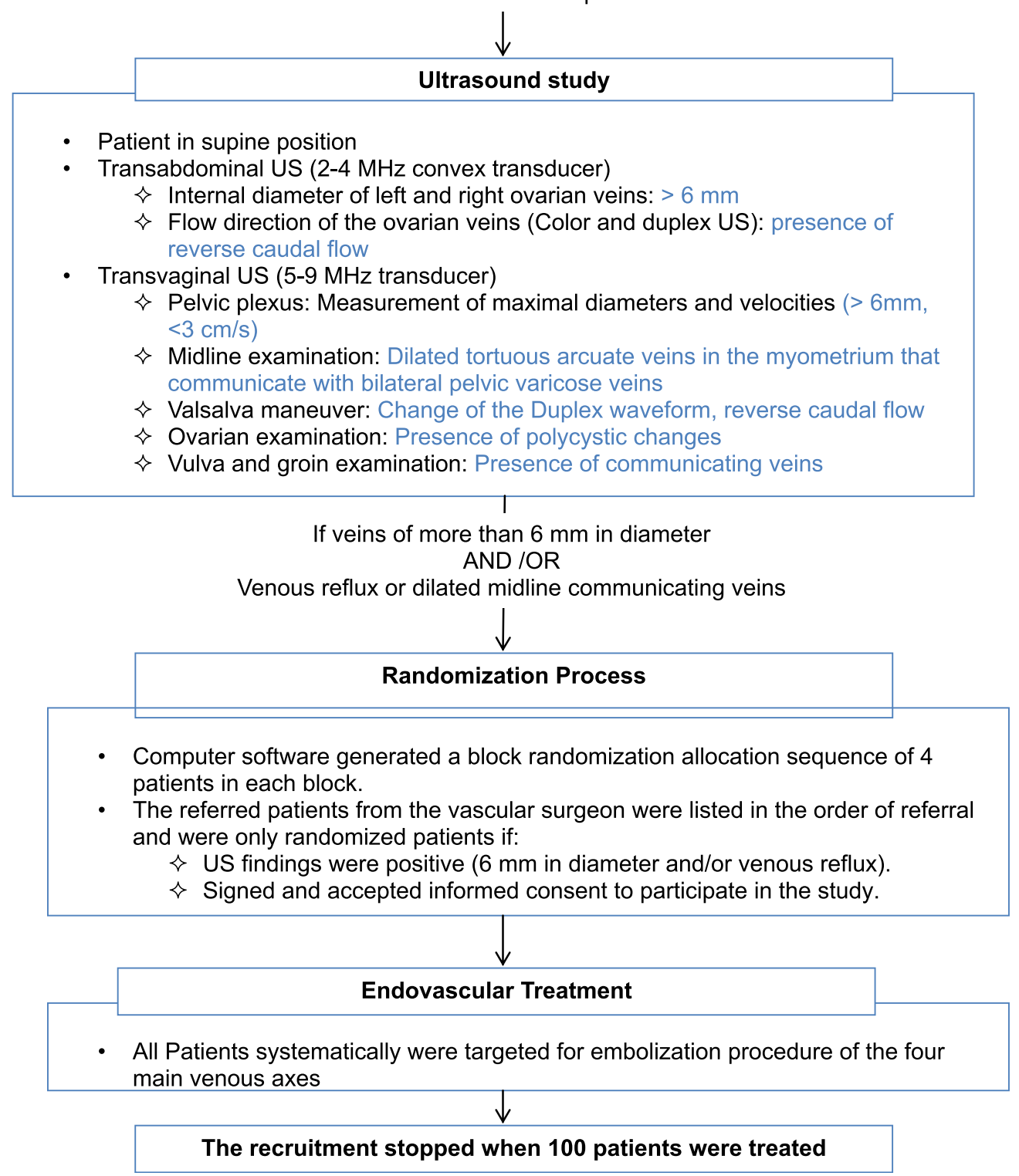

Figure 2. Diagnostic methodology.

compression, total fluoroscopy time, radiation dose (DAP and total air kerma recorded by the fluoroscopy equipment), overall complications, and need for re-embolization (scheduled during the subsequent 12 months).

\section{Follow-up}

Patients in both groups had clinical follow-up at 1, 3, 6, and 12 months after the embolization procedure. Clinical success was defined as improvement or disappearance of the symptoms. VAS score range was $0-10$, defining 0 as no pain and 10 as worst pain possible. Related symptoms were recorded and subjective pain was assessed by the patients at each follow-up consultation. When no improvement was observed, initial symptoms recurred, or transvaginal Doppler ultrasound showed venous reflux or persistence of $>6 \mathrm{~mm}$ venous diameter, re-embolization was scheduled. At the end of the 
Table 1. Inclusion and Exclusion Criteria

Inclusion criteria

Signed informed consent

Age $>18 \mathrm{y}$

Presence of chronic abdominal or pelvic pain for $>6$ months

$>6 \mathrm{~mm}$ pelvic venous caliber measured by transvaginal US

Presence of venous reflux or communicating veins by transvaginal Doppler US

Exclusion criteria

Diagnosed gynecologic or pelvic pathology: endometriosis, pelvic inflammatory disease, postoperative adhesions, adenomyosis, or leiomyoma

Glomerular filtration rate $<60 \mathrm{~mL} / \mathrm{min}$

History of contrast agent reaction

Patients not able to be followed for at least $1 \mathrm{y}$

study, all the patients answered a quality questionnaire by telephone, scoring their satisfaction with the procedure from 0 to 9 , defined as follows: $0-1$, very unsatisfied; $2-3$, unsatisfied; 4-5, neutral; 6-7, satisfied; and 8-9, very satisfied.

\section{Cost Analysis}

The differential costs were calculated by taking into account only the price of the different devices used on each case (FPCs, VPs, and introducer sheaths) assuming the same cost for the rest of the procedure. Prices were estimated according to the hospital charge list. Other costs, such as contrast quantity, other materials, and hospital stay, were not included in the analysis.

\section{Statistical Analysis}

Normality was tested using the Kolmogorov-Smirnoff test. Quantitative variables were expressed as mean and SD or median and range. Qualitative data were expressed as the total number of events and percentages. Continuous variables were analyzed using Student $t$ test as the parametric test and MannWhitney $U$ test as the nonparametric test. The $\chi^{2}$ test and Fisher exact test were used for categorical variables. Time data were represented in a scatterplot, and the evolution of the VAS score over time (1, 3, 6, and 12 months) was plotted in a line chart. All tests of significance were 2 -sided, and $P<.05$ was considered significant. Data were processed and analyzed using IBM SPSS Version 21.0 (IBM Corp, Armonk, New York).

\section{RESULTS}

As shown in Figure 1, 107 patients were assessed for eligibility. Of the patients, 7 were excluded owing to diagnosis of other pelvic pathology $(n=2)$, declining to participate $(n=4)$, or missing the informative consultation $(\mathrm{n}=1)$, and 100 patients were randomly assigned to the 2 groups. No patients were lost at 1, 3, 6, or 12 months of follow-up, and all 100 patients were analyzed. All patients were recruited between January 2014 and January 2015 and followed for 12 months until February 2016.
Table 2. Patient Demographics

\begin{tabular}{|c|c|c|c|}
\hline Characteristic & $\begin{array}{c}\text { FPC } \\
(n=50)\end{array}$ & $\begin{array}{c}\text { VP } \\
(n=50)\end{array}$ & $\boldsymbol{P}$ \\
\hline Age, $y$, mean $\pm S D$ & $41.0 \pm 6.26$ & $44.3 \pm 8.45$ & $.004^{*}$ \\
\hline Living children, median; range & $2.0 ; 0-4$ & $2.0 ; 0-4$ & $.789^{\dagger}$ \\
\hline $\mathrm{BMI}$, mean $\pm \mathrm{SD}$ & $25.2 \pm 1.85$ & $25.2 \pm 2.14$ & $.962 *$ \\
\hline \multicolumn{4}{|l|}{ Symptoms } \\
\hline $\begin{array}{l}\text { Pretreatment VAS score, } \\
\text { median; range }\end{array}$ & $7.0 ; 5-9$ & $8.0 ; 5-10$ & $.004^{\dagger}$ \\
\hline Pain in orthostatic position & $48(96 \%)$ & $50(100 \%)$ & $.247^{\ddagger}$ \\
\hline Pain in supine position & $7(14 \%)$ & $6(12 \%)$ & $.766^{\S}$ \\
\hline Dyspareunia & $27(54 \%)$ & $27(54 \%)$ & $.999^{\S}$ \\
\hline Dysmenorrhea & $27(54 \%)$ & $36(72 \%)$ & $.062^{\S}$ \\
\hline Urinary urgency & $7(14 \%)$ & $6(12 \%)$ & $.766^{\S}$ \\
\hline \multicolumn{4}{|l|}{ History } \\
\hline Ovarian cystic disease & $22(44 \%)$ & $21(42 \%)$ & $.840^{\S}$ \\
\hline Vaginal varicosities & $10(20 \%)$ & $8(16 \%)$ & $.603^{\S}$ \\
\hline Vulvar varicosities & $18(36 \%)$ & $19(38 \%)$ & $.836^{\S}$ \\
\hline Lower limb varices & $45(90 \%)$ & $44(88 \%)$ & $.749^{\S}$ \\
\hline Limb varices surgery & $10(20 \%)$ & $10(20 \%)$ & $.999^{\S}$ \\
\hline \multicolumn{4}{|l|}{ Transvaginal Doppler US } \\
\hline $\begin{array}{l}\text { Maximum right pelvic venous } \\
\text { caliber, median; range }\end{array}$ & $7.0 ; 5-10$ & $7.0 ; 5-11$ & $.938 *$ \\
\hline $\begin{array}{l}\text { Maximum left pelvic venous } \\
\text { caliber, median; range }\end{array}$ & $7.0 ; 5-10$ & $7.0 ; 5-10$ & $.392 *$ \\
\hline Ovarian vein reflux & $40(80 \%)$ & $35(70 \%)$ & $.248^{\S}$ \\
\hline $\begin{array}{l}\text { Waveform change in } \\
\text { Valsalva maneuver }\end{array}$ & $25(50 \%)$ & $30(60 \%)$ & $.315^{\S}$ \\
\hline
\end{tabular}

$\mathrm{BMI}=$ body mass index; FPC = fibered platinum coil; VAS = visual analog scale; $\mathrm{VP}=$ vascular plug.

* Student $t$ test.

${ }^{\dagger}$ Mann-Whitney $U$ test.

${ }^{\ddagger}$ Fisher exact test.

${ }^{\S} \chi^{2}$ test.

\section{Treatment}

In both groups, in $96 \%$ of the cases, embolization was successful in almost all targeted veins (ovarian and internal iliac veins); in 2 patients, the surgeon was unable to achieve embolization of the right ovarian veins because of anatomic variants. The intraoperative variables are provided in Table 3 . To achieve total occlusion of the 4 veins, 15-21 FPCs were needed (Figs 3, 4) and 4-6 VPs were needed (Figs 5, 6) $(P<.001)$. Although the number of devices was lower, the total differential cost (embolization devices and introducer sheath, assuming the same cost for the rest of the procedure) was significantly higher in the VP group. Total procedure time, total fluoroscopy time, and radiation dose were significantly lower in the VP group (Fig 7).

There were 12 minor complications, graded according to Society of Interventional Radiology (SIR) reporting standards (20), $8(16 \%)$ in the FPC group and $4(8 \%)$ in the VP group (Table 4). Major complications involved migration of 4 devices. Three coils migrated from the left internal iliac vein to the right pulmonary arteries $(n=2)$ or left pulmonary artery $(n=1)$. One VP migrated from the left 
Table 3. Intraoperative Variables

\section{Variable}

Embolization devices, median; range

Cost of embolization devices, $€$, median; range

Total procedure time, min, mean \pm SD

Fluoroscopy time, min, mean $\pm \mathrm{SD}$

$\mathrm{DAP}, \mathrm{mGy} \cdot \mathrm{cm}^{2}$, median; range

Total air kerma, mGy, median; range

$\quad$ FPC $(\mathbf{n}=\mathbf{5 0})$
$18.0 ; 15-21$
$2,915.90 ; 2,430.00-3,401.93$
$44.5 \pm 4.09$
$33.4 \pm 4.68$
$384,957.0 ; 118,125.0-632,758.0$
$975.9 ; 233.98-2,132.40$

\begin{tabular}{lc}
\multicolumn{1}{c}{ VP $(\mathbf{n}=\mathbf{5 0})$} & $\boldsymbol{P}$ \\
$4.0 ; 4-7$ & $.000^{*}$ \\
$3,520.00 ; 3,520.00-6,160.00$ & $.000^{*}$ \\
$29.0 \pm 5.95$ & $.000^{\dagger}$ \\
$19.5 \pm 6.14$ & $.000^{\dagger}$ \\
$144,287.5 ; 879,90.0-451,817.0$ & $.000^{*}$ \\
$296.0 ; 189.37-986.49$ & $.000^{*}$
\end{tabular}

$\mathrm{DAP}=$ dose area product; $\mathrm{FPC}=$ fibered platinum coil; $\mathrm{VP}=$ vascular plug.

* Mann-Whitney $U$ test.

${ }^{\dagger}$ Student $t$ test.

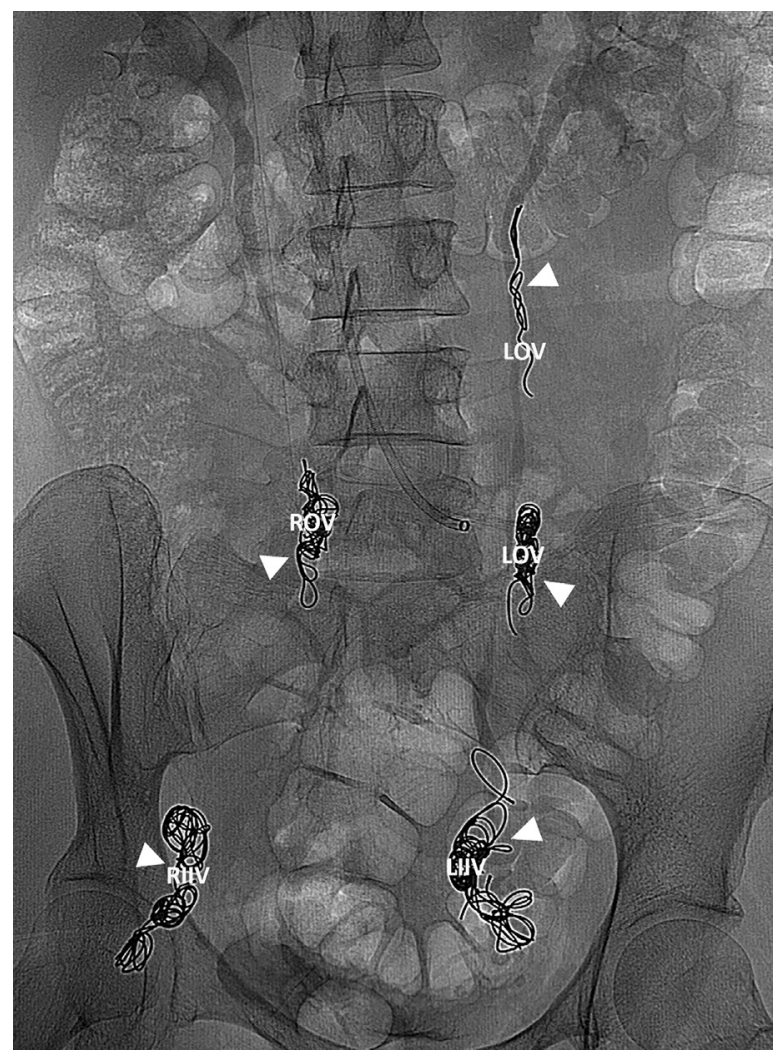

Figure 3. Final outcome of embolization procedure of all 4 targeted pelvic veins. LIIV = left internal iliac vein; LOV = left ovarian vein; RIIV = right internal iliac vein; ROV = right ovarian vein. Arrowheads indicate embolic devices (FPCs).

iliac vein to the right main pulmonary artery $(n=1)$. Migrations to the lung were asymptomatic and diagnosed by chest radiograph that was performed for different reasons (routine radiographs $[\mathrm{n}=3]$ and suspicion of influenza-like illness $[\mathrm{n}=1])$. The coil migrations were discovered 3, 5, and 6 months after the procedure, and the VP migration was discovered 3 months after the procedure. All devices were retrieved with no consequence using right jugular access and a 6-F vascular snare.

\section{Clinical Outcomes}

Clinical success at 1-year follow-up was achieved in all 100 patients with a disappearance of symptoms before the

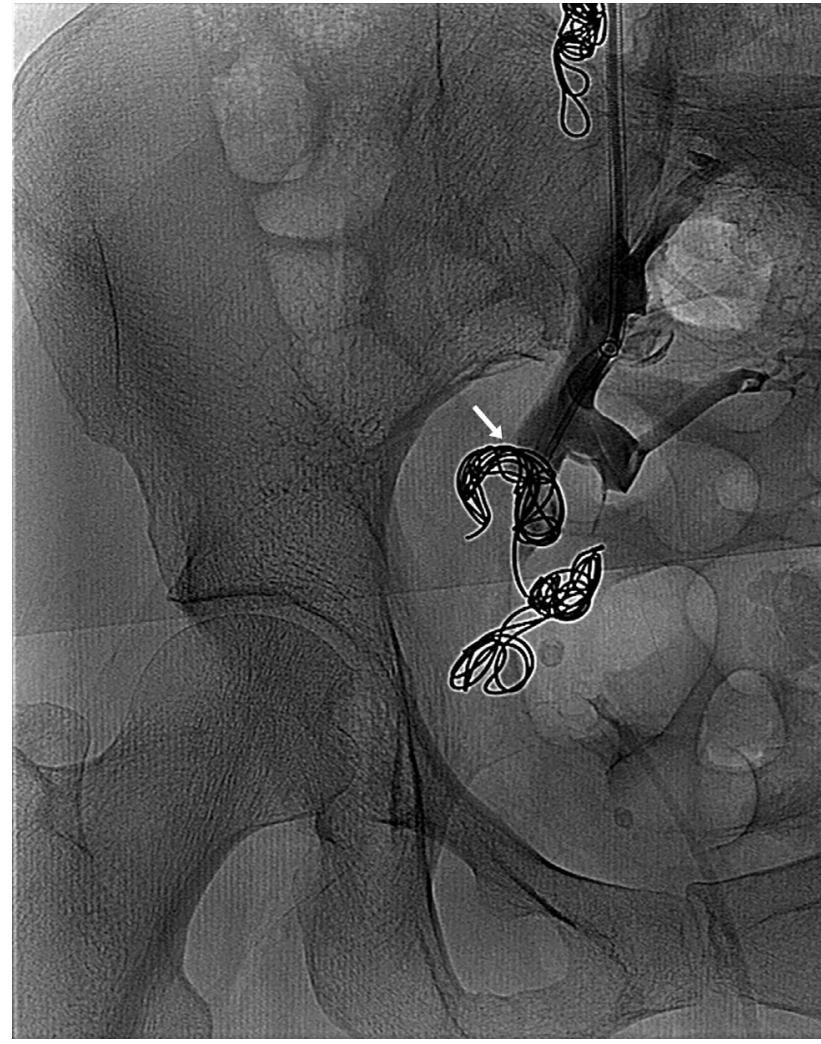

Figure 4. Contrast venography demonstrates complete occlusion of the right internal iliac vein after successful embolization procedure with FPCs.

procedure: dyspareunia (83.3\%), dysmenorrhea (88.7\%), and urinary urgency $(92.8 \%)$. Subjective pain assessed with the VAS scale showed a $90.2 \%$ improvement. The evolution of pain was not significantly different between the 2 groups at any of the time points, although both devices resulted in improvement of chronic pelvic pain in almost all patients (Fig 8). At 1-year follow-up, clinical success did not significantly differ between the groups in regard to improvement of pelvic symptoms or lack of pelvic pain as self-assessed by the VAS (Table 5).

A second embolization procedure was performed in 9 patients owing to lack of improvement in chronic pelvic pain, including 7 patients in the FPC group and 2 patients in the VP group $(P=.095)$. Transvaginal Doppler ultrasound confirmed 


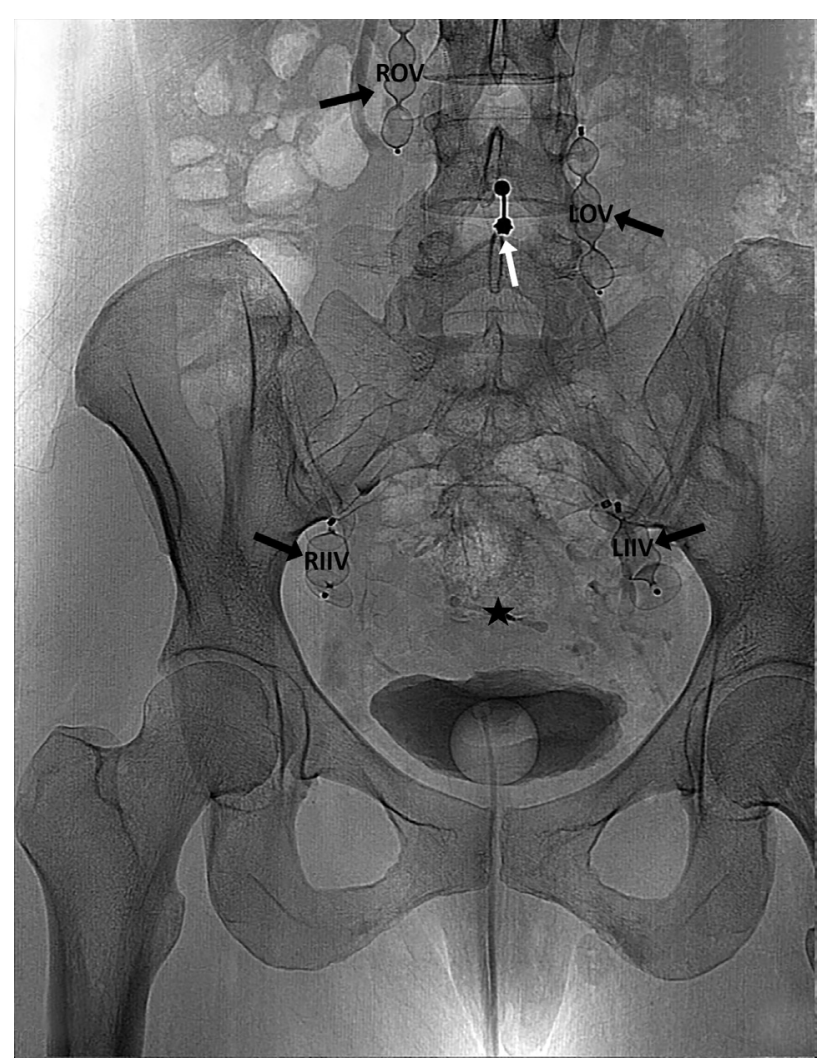

Figure 5. Final outcome of embolization procedure of all 4 targeted pelvic veins. LIIV = left internal iliac vein; LOV = left ovarian vein; RIIV = right internal iliac vein; $R O V=$ right ovarian vein. Black arrows indicate embolic devices (VPs). Black star $=$ intrauterine device; white arrow $=$ navel piercing.

persistent or recurrent varices after embolization, which was evident in all cases. Recurrent varices after embolization were targeted for a new embolization procedure; 2 of the patients were scheduled in the first month, 5 were scheduled in the first 3 months, and 2 were scheduled in the first 6 months after clinical evaluation. After treatment, symptoms improved in all patients. The mean satisfaction score at the end of the study, based on the quality questionnaire conducted by telephone, was 8.1 points \pm 1.05 (range, $0-9$ ). No significant difference was found between the 2 groups (8.2 points \pm 1.04 in FPC vs 7.9 points \pm 1.05 in VP; $P=.061$ ).

\section{DISCUSSION}

It is currently accepted that transcatheter embolization of the pelvic veins is the least invasive and most efficacious management option for pelvic varices (21). Different treatment methods have been proposed with divergent results $(22,23)$, but embolization of ovarian and pelvic veins is considered to have the best outcome $(3,5,6,24)$ and is recommended with a grade 2B level of evidence according to the Society for Vascular Surgery and the American Venous Forum (25). However, few randomized studies are available to compare the long-term outcome $(11,25)$. Some authors recommend the combined use of coils and sclerosing agents (5). Available clinical evidence and randomized studies are

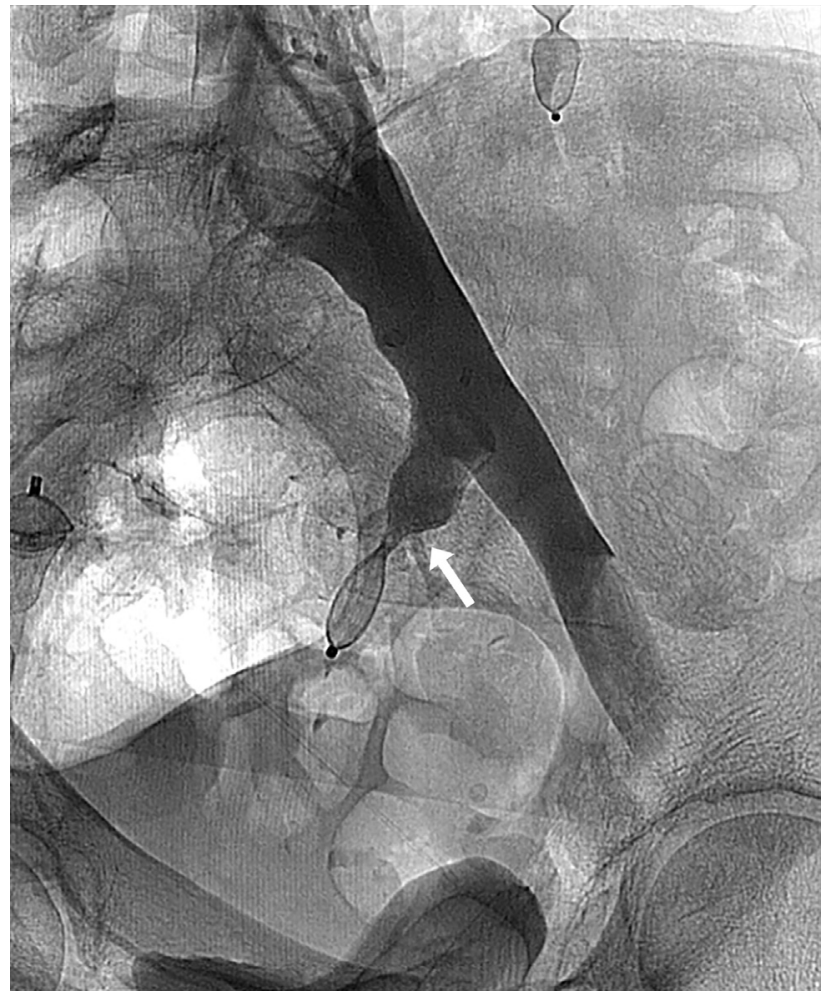

Figure 6. Contrast venography demonstrates complete occlusion of the left internal iliac vein after successful embolization procedure with a VP.

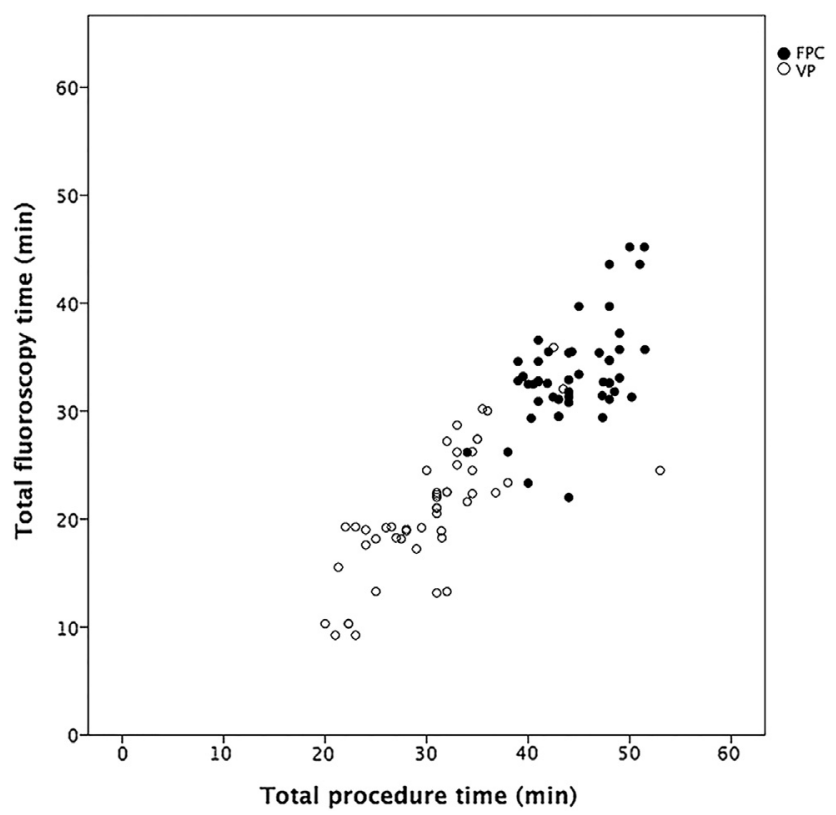

Figure 7. Relationship between total fluoroscopy time (min; y axis) and total procedure time (min; $x$ axis) compared between the 2 embolic devices, FPCs (black dots) and VPs (white dots).

insufficient to compare outcomes and recurrence using only coils or the combined treatment. In the research group experience, the results are similar, so the procedure was simplified as much as possible. Some authors have pointed out that ovarian vein embolization alone is enough to achieve 
Table 4. Complications

\begin{tabular}{lcll} 
Access site hematoma & $2(4 \%)$ & $2(4 \%)$ & $.999^{*}$ \\
$\quad$ Ovarian vein extravasation & $6(12 \%)$ & $2(4 \%)$ & $.232^{*}$ \\
Major complications & & & \\
$\quad$ Device migration & $3(6 \%)$ & $1(2 \%)$ & $.223^{*}$ \\
Total & $11(22 \%)$ & $5(10 \%)$ & $.059^{\dagger}$ \\
\hline
\end{tabular}

$\mathrm{FPC}=$ fibered platinum coil; $\mathrm{VP}=$ vascular plug.

* Fisher exact test.

${ }^{\dagger} \chi^{2}$ test.

good results $(24,26)$. Furthermore, some authors have reported success with embolization of the left ovarian vein alone (6). Ratnam et al (26) recommended embolization only of veins with reflux demonstrated by venography. Larger series demonstrated results in $85 \%-96 \%$ of patients by performing bilateral ovarian and internal iliac vein embolization. The main limitation of these studies is a relatively short follow-up time (27). The present randomized controlled trial was performed to assess whether venous embolization for PCS with VPs could reduce the number of embolic devices and procedure time without significant differences in the clinical success or complication rate compared with FPCs.

The Society for Vascular Surgery and the American Venous Forum recommend coil embolization, plugs, or transcatheter sclerotherapy as standard treatments, with a grade $2 \mathrm{~B}$ level of evidence (17) owing to limited evidence, over other medical or surgically invasive treatments (18). In this study, both

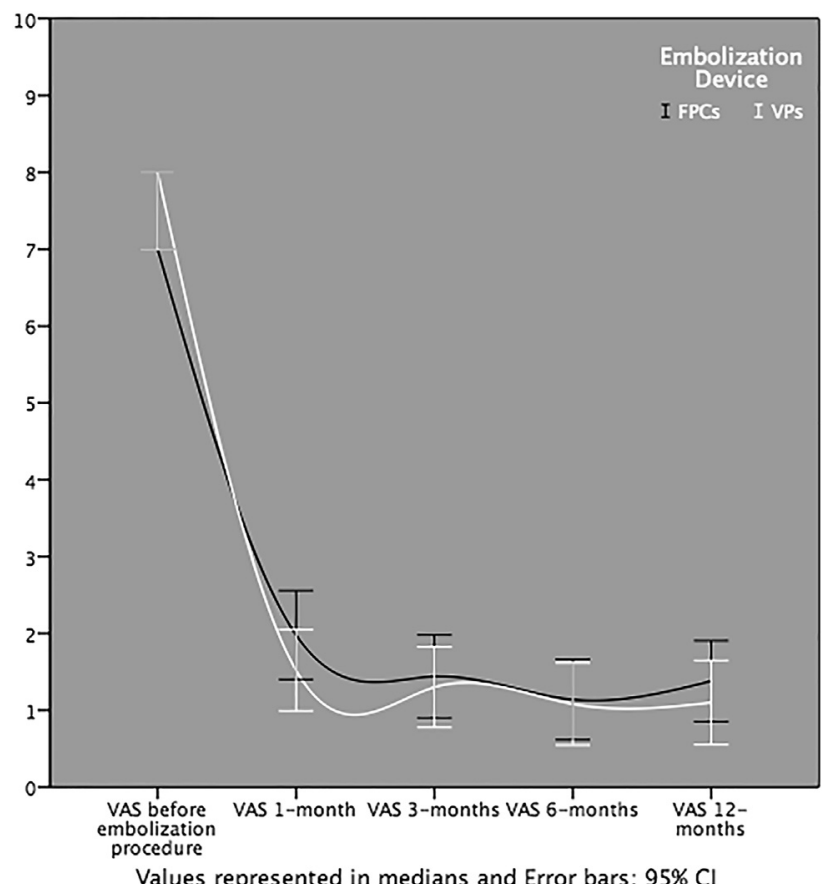

Figure 8. Evolution of pain assessed with VAS over time (before procedure and after 12 months of follow-up) for both groups, represented as medians and error bars with $95 \%$ confidence interval. Black line and black error bars represent FPCs. White line and white error bars represent VPs.
Table 5. Clinical Outcomes at End of 1-Year Follow-up

\begin{tabular}{|c|c|c|c|}
\hline Variable & $\operatorname{FPC}(n=50)$ & VP $(n=50)$ & $\boldsymbol{P}^{*}$ \\
\hline $\begin{array}{l}\text { Disappearance of } \\
\text { dyspareunia }\end{array}$ & $24 / 27(88.9 \%)$ & $21 / 27(77.8 \%)$ & .370 \\
\hline $\begin{array}{c}\text { Disappearance of } \\
\text { dysmenorrhea }\end{array}$ & $24 / 27(88.8 \%)$ & $31 / 35(88.6)$ & .999 \\
\hline $\begin{array}{l}\text { Disappearance of } \\
\text { urinary urgency }\end{array}$ & $6 / 7(85.7 \%)$ & $6 / 6(100 \%)$ & .999 \\
\hline VAS score improvement & $47 / 49(95.9 \%)$ & $48 / 50(96 \%)$ & .999 \\
\hline
\end{tabular}

treatments had high rates of technical and clinical success, as shown in other noncomparative studies $(3,4,6,7,16,17)$. There were no differences in the efficacy of the devices. Complete occlusion confirmed by venography was achieved with both VPs and FPCs, but the number of coils needed was significantly greater than the number of plugs (a mean of 4-5 FPCs per $1 \mathrm{VP})$, as reported in other studies (5-12 coils per $1 \mathrm{VP}$ ) $(13,14,28,29)$. Previous studies also found a significant decrease in procedure and fluoroscopy times in the VP group and a decrease in radiation dose, although the difference was significant in the present study but not in previous ones $(14,29)$. This decrease in procedure time may be caused mainly by the need to verify vessel occlusion between groups of coils in the FPC group. This is especially relevant in this specific pathology, as it reduces the radiation dose in the pelvic area of young fertile women as well as the exposure of the operator.

A disadvantage of VPs is that the largest size must be used to achieve total occlusion of these veins, which usually have a very large diameter. These sizes (Amplatzer Vascular Plug II 14-22 $\mathrm{mm}$ in diameter) require a minimum catheter size of 8-9 F, whereas large coils can usually be delivered with a 5-F catheter. Some authors have reported a longer embolization time for occlusion with a single VP-from 3-5 minutes to $>15-20$ minutes $(12,29)$. All these procedures have been performed in high-flow arteries (splenic, iliac, gastroduodenal), and no difference was observed in this study in the embolization time between devices in the venous territory. Nevertheless, when considering the number of coils needed for total occlusion, most authors $(13,14)$ have reported a significantly lower occlusion time for VPs.

All migrations resulted from internal iliac veins in which embolization had been achieved and occurred 3-6 months after the procedure. Device migrations might be related to the actual oversize diameter percentage, $15 \%-20 \%$ in internal iliac veins. VP manufacturers suggest an oversizing of $30 \%-50 \%$ with respect to the target vessel diameter (30). Despite the low oversize estimation, only $2 \%$ ( 1 of 50 ) of patients presented with device migration in the VP group and $6 \%(3 / 50)$ of patients presented with device migration in the FPC group without statistical significance. The pelvic venous plexus has different physiologic and histologic characteristics compared with arteries. Veins have thinner walls with large lumen diameters and the lack of elastic 
membrane in the tunica media, resulting in low-pressure, low-resistance vessels with high capacitance compared with arteries (31). These characteristics can predispose for device migration because of a higher passive compliance as well as an opposite blood flow when performing an embolization procedure in pelvic veins compared with an arterial embolization. Other authors have published similar results regarding coil migration: Venbrux et al (3), 3.6\% of patients (2 of 56); Laborda et al (7), 1.9\% of patients (4 of 202); Kim et al (5), $1.5 \%$ of patients ( 2 of 127 ); and Kwon et al (6), $3 \%$ of patients ( 2 of 67$)$ as well as others (4).

Among the main limitations of the present study are the significant differences between groups in age and VAS score before treatment, both of which were slightly higher in the VP group despite randomization. However, these differences did not have clinical repercussions (severe pain scores on the VAS were 7-9). Another limitation is that clinical success, referring to pain and discomfort, is difficult to measure objectively. A subjective scale, such as the VAS, can be influenced by other concomitant disorders and environmental or psychological conditions. Cost calculation is another limitation of the study. Prices for these devices differ between countries and even between regions of the same country. In this study, VPs were significantly more expensive, but other studies with very similar data demonstrated a significant cost savings of between $\$ 410$ and $\$ 1,375$ when using VPs in gastroduodenal and internal iliac arteries $(13,29)$. The total cost was not calculated, only the cost of the embolization device. The total material, contrast media, hospital stay, operating time, and complication costs (eg, material for device retrieval) were not included in the analysis. As a practical consideration and taking reimbursement into account, each hospital should interpret and use these data for application in their local environment.

In conclusion, venous embolization for the treatment of PCS is equally safe and effective with FPCs or VPs, with a significant improvement in pelvic symptoms for PCS. Fewer VPs were needed to achieve total occlusion with the same clinical outcome as FPCs, and the procedure and fluoroscopy times and radiation dose were also reduced.

\section{REFERENCES}

1. Taylor HC. Vascular congestion and hyperemia; their effect on function and structure in the female reproductive organs; etiology and therapy. Am J Obstet Gynecol 1949; 57:654-668.

2. Ganeshan A, Upponi S, Hon L-Q, Uthappa MC, Warakaulle DR, Uberoi R. Chronic pelvic pain due to pelvic congestion syndrome: the role of diagnostic and interventional radiology. Cardiovasc Intervent Radiol 2007; 30: 1105-1111.

3. Venbrux AC, Chang AH, Kim HS, et al. Pelvic congestion syndrome (pelvic venous incompetence): impact of ovarian and internal iliac vein embolotherapy on menstrual cycle and chronic pelvic pain. J Vasc Interv Radiol 2002; $13(2$ pt 1):171-178.

4. Maleux G, Stockx L, Wilms G, Marchal G. Ovarian vein embolization for the treatment of pelvic congestion syndrome: long-term technical and clinical results. J Vasc Interv Radiol 2000; 11:859-864.

5. Kim HS, Malhotra AD, Rowe PC, Lee JM, Venbrux AC. Embolotherapy for pelvic congestion syndrome: Iong-term results. J Vasc Interv Radiol 2006; 17(2 pt 1):289-297.

6. Kwon SH, Oh JH, Ko KR, Park HC, Huh JY. Transcatheter ovarian vein embolization using coils for the treatment of pelvic congestion syndrome. Cardiovasc Interv Radiol 2007; 30:655-661.
7. Laborda A, Medrano J, de Blas I, Urtiaga I, Carnevale FC, de Gregorio MA. Endovascular treatment of pelvic congestion syndrome: visual analog scale (VAS) long-term follow-up clinical evaluation in 202 patients. Cardiovasc Intervent Radiol 2013; 36:1006-1014.

8. Daniels JP, Champaneria R, Shah L, Gupta JK, Birch J, Moss JG. Effectiveness of embolization or sclerotherapy of pelvic veins for reducing chronic pelvic pain: a systematic review. J Vasc Interv Radiol 2016; 27: 1478-1486.e8.

9. Monedero JL, Ezpeleta SZ, Perrin M. Pelvic congestion syndrome can be treated operatively with good long-term results. Phlebology 2012; 27(suppl 1):65-73.

10. van der Vleuten CJM, van Kempen JAL, Schultze-Kool LJ. Embolization to treat pelvic congestion syndrome and vulval varicose veins. Int $J$ Gynaecol Obstet 2012; 118:227-230.

11. Smith PC. The outcome of treatment for pelvic congestion syndrome. Phlebology 2012; 27(suppl 1):74-77.

12. Wang W, Li H, Tam MD, Zhou D, Wang DX, Spain J. The Amplatzer Vascular Plug: a review of the device and its clinical applications. Cardiovasc Intervent Radiol 2012; 35:725-740.

13. Pech M, Kraetsch A, Wieners G, et al. Embolization of the gastroduodenal artery before selective internal radiotherapy: a prospectively randomized trial comparing platinum-fibered microcoils with the Amplatzer Vascular Plug II. Cardiovasc Intervent Radiol 2009; 32:455-461.

14. Ryer EJ, Garvin RP, Webb TP, Franklin DP, Elmore JR. Comparison of outcomes with coils versus vascular plug embolization of the internal iliac artery for endovascular aortoiliac aneurysm repair. J Vasc Surg 2012; 56: 1239-1245.

15. Sarwar A, Esparaz AM, Tapper EB, et al. Comparison of vascular plugs and pushable coils for variceal embolization after TIPS. AJR Am J Roentgenol 2017; 208:650-655.

16. Basile A, Marletta G, Tsetis D, Patti MT. The Amplatzer vascular plug also for ovarian vein embolization. Cardiovasc Intervent Radiol 2008; 31:446-447.

17. Thors A, Haurani MJ, Gregio TK, Go MR. Endovascular intervention for pelvic congestion syndrome is justified for chronic pelvic pain relief and patient satisfaction. J Vasc Surg Venous Lymphat Disord 2014; 2:268-273.

18. Lopez AJ. Female pelvic vein embolization: indications, techniques, and outcomes. Cardiovasc Intervent Radiol 2015; 38:806-820.

19. Urbaniak GC, Plous S. Research Randomizer (Version 4.0). 2013 Available at: http://www.randomizer.org/. Accessed November 25, 2013.

20. Black CM, Thorpe K, Venbrux A, et al. Research reporting standards for endovascular treatment of pelvic venous insufficiency. J Vasc Interv Radiol 2010; 21:796-803.

21. Meissner MH, Gibson K. Clinical outcome after treatment of pelvic congestion syndrome: sense and nonsense. Phlebology 2015; 30(1 suppl):73-80.

22. Hobbs JT. Varicose veins arising from the pelvis due to ovarian vein incompetence. Int J Clin Pract 2005; 59:1195-1203.

23. Gargiulo T, Mais V, Brokaj L, Cossu E, Melis GB. Bilateral laparoscopic transperitoneal ligation of ovarian veins for treatment of pelvic congestion syndrome. J Am Assoc Gynecol Laparosc 2003; 10:501-504.

24. Capasso P, Simons C, Trotteur G, Dondelinger RF, Henroteaux D, Gaspard U. Treatment of symptomatic pelvic varices by ovarian vein embolization. Cardiovasc Intervent Radiol 1997; 20:107-111.

25. Gloviczki P, Comerota AJ, Dalsing MC, et al. The care of patients with varicose veins and associated chronic venous diseases: clinical practice guidelines of the Society for Vascular Surgery and the American Venous Forum. J Vasc Surg 2011; 53(5 suppl):2S-48S.

26. Ratnam LA, Marsh P, Holdstock JM, et al. Pelvic vein embolisation in the management of varicose veins. Cardiovasc Intervent Radiol 2008; 31: 1159-1164.

27. Kies DD, Kim HS. Pelvic congestion syndrome: a review of current diagnostic and minimally invasive treatment modalities. Phlebology 2012; 27(suppl 1):52-57.

28. Bulla K, Hubich S, Pech M, Löwenthal D, Ricke J, Dudeck O. Superiority of proximal embolization of the gastroduodenal artery with the Amplatzer Vascular Plug 4 before yttrium-90 radioembolization: a retrospective comparison with coils in 134 patients. Cardiovasc Intervent Radiol 2014; 37:396-404

29. Pellerin $O$, Caruba $T$, Kandounakis $Y$, et al. Embolization of the internal iliac artery: cost-effectiveness of two different techniques. Cardiovasc Intervent Radiol 2008; 31:1088-1093.

30. Abdel Aal AK, Massoud MO, Elantably DM. Does the type and size of Amplatzer Vascular Plug affect the occlusion time of pulmonary arteriovenous malformations? Diagn Interv Radiol 2017; 23:61-65.

31. Lee BB, Nicolaides AN, Myers K, et al. Venous hemodynamic changes in lower limb venous disease: the UIP consensus according to scientific evidence. Int Angiol 2016; 35:236-352. 